\title{
Article
}

Arq Neuropsiquiatr 2011;69(3):460-465

\section{Pattern of P50 suppression deficit in patients with epilepsy and individuals with schizophrenia}

\author{
Jefferson Becker ${ }^{1}$, Irenio Gomes da Silva Filho ${ }^{1,3}$, \\ Hélio Fernandes da Silva Filho', Alice Schuch", \\ Fernanda Lia de Paula Ramos ${ }^{4}$, Eduardo Sörensen Ghisolfi4, \\ Diogo Rizzato Lara ${ }^{2,4}$, Jaderson Costa da Costa ${ }^{1,3}$
}

\begin{abstract}
Objective: To identify P50 suppression in patients with epilepsy, to investigate the effect of seizure control on P50 suppression, and to compare epilepsy patients with individuals with schizophrenia and healthy volunteers. Method: P50 evoked potential parameters and P50 suppression were studied crossectionally in patients with uncontrolled or controlled epilepsy, in individuals with schizophrenia and in healthy volunteers. Results: Individuals with schizophrenia had significantly smaller conditioning stimulus (S1) amplitude, and patients with epilepsy had larger test stimulus (S2) amplitude. Mean S2/S1 ratio was $0.71 \pm 0.33$ for patients with uncontrolled epilepsy; $0.68 \pm 0.36$ for patients with controlled epilepsy; $0.96 \pm 0.47$ for individuals with schizophrenia, and $0.42 \pm 0.24$ for healthy volunteers. Conclusion: The sensory filter of patients with epilepsy is altered, and this alteration is not associated with seizure control. Also, it works differently from the sensory filter of individuals with schizophrenia.
\end{abstract}

Key words: epilepsy, P50 auditory evoked potential, schizophrenia, sensory filter.

\section{Padrão do déficit de supressão do P50 em pacientes com epilepsia e em indivíduos com esquizofrenia}

\section{RESUMO}

Objetivo: Identificar se existe déficit de supressão do P50 em pacientes com epilepsia, verificar a influência do controle das crises nesse déficit, comparando com pacientes com esquizofrenia e com voluntários saudáveis. Método: Os parâmetros do potencial evocado P50 e sua supressão foram estudados, com um corte transversal, em pacientes com epilepsia controlada ou não, esquizofrenia e em voluntários saudáveis. Resultados: Indivíduos com esquizofrenia apresentam uma amplitude de S1 significativamente menor que os demais, sendo que os pacientes com epilepsia apresentavam uma resposta S2 de maior amplitude. A média da razão S2/S1 foi de 0,71 00,33 nos pacientes com epilepsia não controlada; $0,68 \pm 0,36$ naqueles com epilepsia controlada; $0,96 \pm 0,47$ nos com esquizofrenia e 0,42 $\pm 0,24$ nos controles normais. Conclusão: $\bigcirc$ filtro sensitivo de pacientes com epilepsia é alterado, e essa alteração não está associada com o controle

\section{Correspondence} Jefferson Becker Rua Ely Costa, 60 90480-110 Porto Alegre RS - Brasil E-mail: jeffersonbecker@hotmail.com

Received 4 August 2010

Received in final form 23 February 2011 Accepted 02 March 2011 das crises. Além disso, ele funciona de forma diferente do filtro sensitivo dos indivíduos com esquizofrenia.

Palavras-chave: epilepsia, potencial evocado auditivo P50, esquizofrenia, filtro sensitivo.

Pontifícia Universidade Católica do Rio Grande do Sul, Porto Alegre RS, Brazil: ${ }^{1}$ Neurology Service, Hospital São Lucas: ${ }^{2}$ Psychiatry Service, Hospital São Lucas; ${ }^{3}$ Department of Internal Medicine, Faculdade de Medicina; ${ }^{4}$ Department of Biochemistry, Faculdade de Biociências. 
Epilepsy is a syndrome characterized by recurrent seizures that may be idiopathic or secondary to neurological or metabolic lesions. Despite the frequent advancements in diagnosis and pharmacological treatment, 30 to $40 \%$ of patients with epilepsy are resistant to medication ${ }^{1}$. For these patients, epilepsy surgery has become an increasingly important therapeutic option. The most common epileptic syndromes in adults are those of the temporal lobe ${ }^{1,2}$, and the seizures of the limbic mesial temporal structures account for 60 to $75 \%$ of the cases of partial epilepsy ${ }^{2}$.

The P50 evoked potential is a preattentional positive wave that usually appears 30 to $90 \mathrm{~ms}$ after auditory stimuli. In the paradigm of paired clicks, two stimuli are given at a short interval. The response to the first (conditioning) stimulus (S1) activates brain mechanisms that reduce the response to the second (test) stimulus (S2). The finding of a smaller ratio or a greater difference between stimuli indicates better inhibition or, in other words, a more effective gating of irrelevant stimuli ${ }^{3-13}$. Several studies have shown that the P50 evoked potential obtained using the paradigm of paired conditioning-test stimuli is a very effective method for the analysis of the functioning of the sensory filter. The response of healthy control individuals is significantly different from that of patients with certain neuropsychiatric disorders. Of such disorders, schizophrenia has been the object of most studies ${ }^{3-10,12-15}$.

Several studies have analyzed the P50 suppression deficit in patients with different neurological disorders. Their results show that different brain structures are implicated in the reduction of the sensory gating ability studied by the P50 paradigm ${ }^{5,8,10,15,16}$. The sensory filter depends on complex brain circuits. In schizophrenia, the decrease in the S2/S1 ratio is usually due to a decrease in S1 amplitude ${ }^{11,17-20}$, whereas in other disorders, such as Machado-Joseph disease ${ }^{18}$ and traumatic brain injury ${ }^{4}$, S2 amplitude is increased, which may indicate the existence of different mechanisms affecting the sensory filter.

Few studies about P50 suppression in patients with epilepsy have been found in the literature ${ }^{14,21-24}$. Epilepsy may affect several brain structures that are important for the functioning of the sensory filter. Therefore, an alteration of this filter may be expected in individuals with epilepsy. The purposes of this study were to identify whether P50 suppression deficit is found in patients with epilepsy that underwent surgical treatment; to investigate the effect of seizure control on P50 suppression deficit, and to study the behavior of S1 and S2 amplitudes in patients with epilepsy, individuals with schizophrenia and healthy volunteers.

\section{METHOD}

Fifty-two patients with epilepsy (ages $=18$ to 60 years) were selected from the Epilepsy Surgery Program of Hos- pital São Lucas at PUCRS to participate in this crosssectional study. All patients had been on a stable therapeutic scheme for at least two months before enrollment; surgery of the patients that had undergone surgical treatment of epilepsy was performed at least three months before enrollment. Forty other individuals that met the DSM-IV criteria for the diagnosis of schizophrenia after psychiatric evaluation were selected both from public and private health institutions. Finally, forty healthy volunteers were enrolled from the community as a control group. The groups were balanced as to sex and age.

Exclusion criteria were: any other psychiatric disease identified by means of a standardized questionnaire (Mini International Neuropsychiatric Interview) ${ }^{25}$; use of illicit drugs in the previous month; any other neurological disease; deafness; and family history of psychotic disorders. Patients with schizophrenia were excluded also when taking any atypical antipsychotic drug.

Study participants were divided in four groups as follows:

- Group 1 - Uncontrolled epilepsy ( $\mathrm{n}=26)$ : patients with uncontrolled epilepsy after surgery or while awaiting surgery; subjects had temporal $(\mathrm{n}=13)$, frontal $(n=5)$, multifocal $(n=4)$, parietal $(n=3)$ or occipital $(n=1)$ lobe epilepsy.

- Group 2 - Controlled epilepsy ( $\mathrm{n}=26)$ : patients with epilepsy who had undergone surgical treatment and had been seizure-free for the past two years; subjects had temporal $(n=24)$, frontal $(n=1)$ or occipital $(n=1)$ lobe epilepsy.

- Group 3 - Schizophrenia ( $\mathrm{n}=40)$ : individuals with a diagnosis of schizophrenia.

- Group 4 - Controls $(\mathrm{n}=40)$ : individuals with no neuropsychiatric disease.

Patients or their legal guardians signed an informed consent term before examination. Patients with schizophrenia and healthy volunteers signed the same consent. The study was submitted to and approved by the Ethics Committee of Hospital São Lucas at PUCRS and it conforms to the provisions of the Declaration of Helsinki in 1995.

The examinations were performed according to the protocol reported by Nagamoto et al. ${ }^{12}$, except that the limit of \pm 10 ms was slightly extended when the beginning and the end of the wave were clearly identified. Electroencephalographic activity was recorded from a disk electrode affixed to the vertex $(\mathrm{Cz})$ and referenced to both mastoids. The mean signal was registered in two channels, one for each side of the cranium, and amplified 20,000 times with a bandpass filter between $10 \mathrm{~Hz}$ and $10 \mathrm{kHz}$. EEG was collected during $1 \mathrm{~s}$ for each paired stimulus presented. Auditory stimuli (clicks) were presented in a conditioning-testing paradigm with an inter- 
pair interval of $500 \mathrm{~ms}$ and interstimuli interval of $10 \mathrm{~s}$. A 0.04 ms square wave pulse was amplified in the auditory frequencies $(20-12,000 \mathrm{~Hz})$ and delivered through earphones that produce a $2.5 \mathrm{~ms}$ sound with an intensity of $60 \mathrm{~dB}$ sound pressure level above the auditory acuity threshold. Thirty non-rejected waves were added together to give a grand average signal, which was used for analysis. The most positive peak between 30 and 90 ms after the conditioning stimulus (S1) was selected as the P50 final latency and the wave amplitude was measured relative to the previous negativity, determining the initial latency and the first P50 wave. The test wave (S2) was determined using the corresponding peak between $500 \pm 10$ ms away from S1 latency and its amplitude also

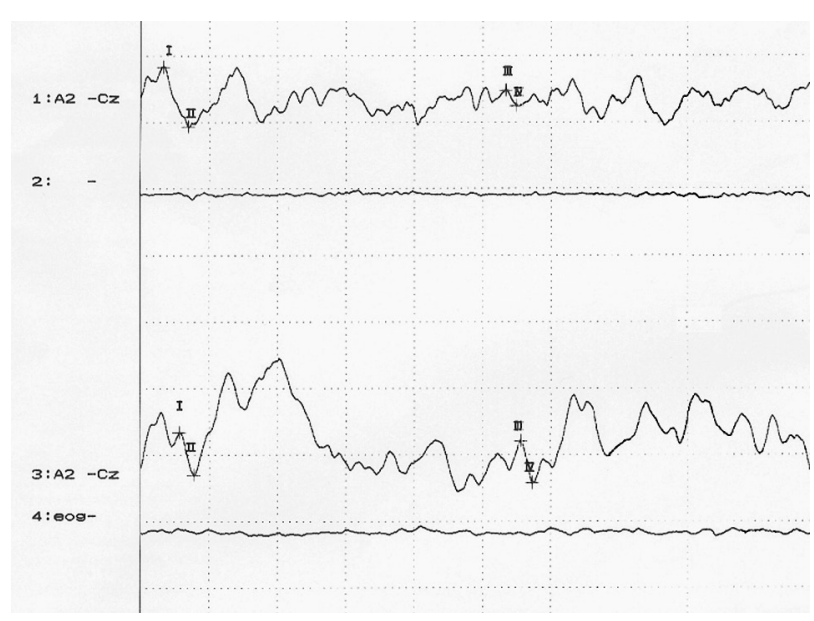

Figure. P50 waveforms. Grand average wave forms: channel 1 normal P50 suppression (control individual); channel 3 - deficit in P50 suppression (patient using typical antipsychotic); channels 2 (control individual) and 4 (patient using typical antipsychotic) electrooculogram showing no ocular artifacts. measured relative to the previous negative peak. A neurophysiologist blinded to the identification of patients or controls analyzed results. P50 suppression was calculated as the ratio of the amplitude of the wave generated by the second stimulus to the amplitude of the wave generated by the first stimulus (S2/S1) and as the difference between S2 and S1 amplitudes (S1-S2) (Figure). Whenever a S2/S1 ratio greater than 2.00 was found, this value was arbitrarily adopted not to distort the mean of a given group, following Nagamoto's recommendation ${ }^{12}$.

P50 suppression parameters (ratio and difference) and $\mathrm{S} 1$ and $\mathrm{S} 2$ amplitudes were the variables for comparison. ANOVA was used to compare group means, and a post hoc Bonferroni test to compare means between each two groups. Frequencies were compared with the chi-square test. The level of significance was 95\% ( $\mathrm{p}<0.05)$. An additional analysis of patients in Group 1 was conducted: those that underwent surgery $(n=17)$ and those that did not $(n=9)$ were separated. We calculated that this sample size (17 and 9 patients) would have an $80 \%$ power to show a difference of 0.30 in mean S2/ $\mathrm{S} 1$ ratios. The software SPSS 11.5 for Windows was used for statistical analysis.

\section{RESULTS}

Age range and mean age \pm standard deviation (years) in the four groups were: Group 1 (uncontrolled epilepsy), 18 to $50,33.7 \pm 10.2$; Group 2 (controlled epilepsy), 18 to

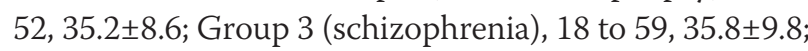
Group 4 (controls), 21 to $64,31.1 \pm 9.9$. No statistically significant difference was found in mean age between groups $(\mathrm{p}=0.157)$. The number of women in each group was: Group 1, 10 (38.5\%); Group 2, 12 (46.2\%); Group 3, 18 (45.0\%); Group 4, 15 (37.5\%). No statistically signif-

Table. Comparison of final means of S1 and S2 wave amplitudes and P50 suppression between groups.

\begin{tabular}{|c|c|c|c|c|}
\hline Variable & S1 Amplitude & S2 Amplitude & $\mathrm{P} 50$ ratio (S2/S1) & P50 difference (S1-S2) \\
\hline \multicolumn{5}{|c|}{ Final mean \pm standard deviation } \\
\hline Group 1 & $6.49 \pm 2.61$ & $4.36 \pm 2.04$ & $0.71 \pm 0.33$ & $2.13 \pm 2.43$ \\
\hline Group 2 & $6.76 \pm 3.41$ & $4.29 \pm 2.57$ & $0.68 \pm 0.36$ & $2.46 \pm 2.91$ \\
\hline Group 3 & $3.70 \pm 3.07$ & $3.10 \pm 1.77$ & $0.96 \pm 0.47$ & $0.60 \pm 2.09$ \\
\hline Group 4 & $5.72 \pm 2.81$ & $2.22 \pm 1.54$ & $0.42 \pm 0.24$ & $3.45 \pm 2.71$ \\
\hline \multicolumn{5}{|l|}{ P-Value } \\
\hline ANOVA & $<0.001$ & $<0.001$ & $<0.001$ & $<0.001$ \\
\hline $1 \times 2$ & 0.918 & 0.754 & 0.743 & 0.657 \\
\hline $1 \times 3$ & 0.010 & $<0.001$ & 0.013 & 0.008 \\
\hline $1 \times 4$ & $<0.001$ & 0.267 & $<0.001$ & 0.048 \\
\hline $2 \times 3$ & 0.045 & $<0.001$ & 0.012 & 0.004 \\
\hline $2 \times 4$ & 0.001 & 0.183 & 0.003 & 0.164 \\
\hline $3 \times 4$ & 0.021 & 0.003 & $<0.001$ & $<0.001$ \\
\hline
\end{tabular}


icant difference was found in sex distribution between groups $(\mathrm{p}=0.851)$.

The comparison of mean amplitudes of the four groups showed a significant difference in both $\mathrm{S} 1$ and S2 amplitudes (ANOVA; $\mathrm{p}<0.001$ ). The comparison of groups two by two showed that the amplitude of S1 in the group of patients with schizophrenia was significantly smaller than in the other groups. A difference in the amplitude of $\mathrm{S} 2$ was found in all comparisons between groups except in the comparison between the groups of patients with uncontrolled epilepsy and of seizure-free patients (Table).

Mean S2/S1 ratio in the group of patients with uncontrolled epilepsy was $0.71 \pm 0.33$ and ranged from 0.27 to 1.79. In seizure-free patients, mean ratio was $0.68 \pm 0.36$ and the range was 0.09 to 1.56 . The group of individuals with schizophrenia had a mean S2/S1 ratio of $0.96 \pm 0.47$, and the range was 0.31 to 2.00 . The group of healthy controls had a mean suppression ratio of $0.42 \pm 0.24$, ranging from 0.02 to 0.99 . A statistically significant difference between groups was found in the frequency of suppression greater than $50 \%(\mathrm{p}<0.001)$, as well as of suppression greater than $60 \%(\mathrm{p}<0.001)$. The analysis of S2/S1 ratios of the four groups showed a significant difference (ANOVA; $\mathrm{p}<0.001$ ). When groups were compared two by two, a significant difference was found between all groups except between the groups of patients with uncontrolled epilepsy and of seizure-free patients (Table).

The analysis of data for patients in Group 1, comparing those that underwent surgery and those that did not, revealed that the S2/S1 ratio was similar in these two subgroups: $0.70 \pm 0.37$ and $0.73 \pm 0.23$, respectively $(\mathrm{p}=0.801)$. When we analyzed these subgroups as independent groups using ANOVA, the comparison of means in the 5 groups revealed an equally significant difference $(p<0.001)$. The comparison of these two subgroups ( $p a-$ tients that underwent surgery and those that did not) with the group of patients with controlled epilepsy did not reveal any significant differences $(\mathrm{p}=0.854$ and $\mathrm{p}=0.668$, respectively). Statistically significant differences were only found in the comparison of these subgroups with the group of normal control subjects $(\mathrm{p}=0.002$ and $\mathrm{p}=0.001$, respectively) and with the group of patients with schizophrenia ( $\mathrm{p}=0.046$ and $\mathrm{p}=0.044$, respectively).

The results of the analysis of the differences between the P50 components (S1-S2) are shown in Table. In group 1 , the mean value was $2.13 \pm 2.43$ and the range was -1.82 to 9.37. In Group 2, the mean value was $2.46 \pm 2.91$, and the range was -3.15 to 10.42 . In Group 3, mean value was $0.60 \pm 2.09$ and the range was -4.09 to 8.53 . In Group 4 , the mean was $3.45 \pm 2.71$, and the range was 0.03 to 14.79. The frequency of negative differences was significantly different between the four groups $(p<0.001)$. The analysis of variance (ANOVA) between the differences of $\mathrm{P} 50$ potentials (S1-S2) in the four groups showed different means $(p<0.001)$. When groups were compared two by two, a significant difference between all groups was found, except for groups 1 and 4 when compared with group 2 .

\section{DISCUSSION}

A statistically significant difference in P50 suppression was found in patients with epilepsy compared with healthy volunteers. Findings were significant for both the S2/S1 ratio and the S1-S2 difference. However, suppression deficit was smaller than that found in individuals with schizophrenia. Few studies have analyzed the P50 auditory evoked potential in patients with epilepsy ${ }^{14,21-24}$. One of them has evaluated the double-click paradigm, but it did not study the existence of a suppression deficit $^{14}$. Kurthem et al. found that the mean S2/S1 ratio in epilepsy patients was found to lie in the range of 'pathological' groups rather than that of the normal control groups. Unfortunately, their study did not include a control group as they were doing invasive P50 recording. Boutros et al. did not find differences in the sensory gating (S2/S1 ratio and S1-S2 difference) between patients with focal epilepsy and controls. It must be emphasized that the epilepsy patients and the healthy controls performed the examination in different laboratories and with different machines which may affect the responses. Recently, Rosburg et al. studying epilepsy patients with unilateral or bilateral hippocampal sclerosis did find a pronounced response suppression which was not different between these groups.

Suppression deficit was significantly greater in individuals with schizophrenia than in those with epilepsy. Furthermore, significantly smaller S1 amplitude was found in the group of individuals with schizophrenia when compared with healthy volunteers and with patients with epilepsy. However, in patients with epilepsy, the main effect was due to an increase in the amplitude of the $\mathrm{S} 2$ response. Such increase was found in all groups of patients with epilepsy, regardless of seizure control. In agreement with the results reported here, several authors have found that the decrease in P50 suppression in patients with schizophrenia is due to a smaller amplitude of S1, although some increase in the amplitude of $\mathrm{S} 2$ has also been reported ${ }^{11,17-20}$. One possible explanation is that there may be a direct effect on the inhibition of the response to the second stimulus in epilepsy, thus leading to greater amplitude of S2. Boutros et al. (2006) did not find differences in the amplitudes of the P50 responses between patients with focal epilepsy and healthy controls which differ from schizophrenic patients where the P50 are rather consistently decreased in amplitude. 
Deficits in the sensory filter have also been detected by the P50 paradigm in many other diseases, such as Alzheimer's disease ${ }^{7}$, and posttraumatic stress disorder $(\mathrm{PTSD})^{26}$. The P50 ratio was also increased in chronic cocaine $^{27}$ and marihuana users ${ }^{28}$, as well as in cases of acute ingestion of alcohol ${ }^{27}$. Moreover, clinically non-affected relatives of individuals with schizophrenia may have a P50 suppression deficit ${ }^{13}$. Since individuals with schizophrenia ${ }^{8,11-13,17,19,20}$, epilepsy ${ }^{14,21-24}$, Huntington's disease $(\mathrm{HD}){ }^{15}$, traumatic brain injury, ${ }^{4}$ Machado-Joseph disease $^{18}$, and migraine ${ }^{16}$ show a deficit in the P50 suppression, we wonder what point in common these diseases and disorders may have that results in their being associated with a dysfunction of the sensory filter. It seems to be practically impossible to find one single structure in common, although several similarities are definitely observed. For example, HD and migraine are associated with dysfunctions of brain stem structures. In HD, there seems to be disinhibition of cholinergic neurons of the pedunculus-pontine nucleus due to a loss of the afferent inhibitory impulse in the locus coeruleus, which is characteristically degenerated in this disease. Such structures seem to be the same involved in migraine ${ }^{16}$. As to schizophrenia, studies show an enlargement of the Sylvian fissure, frontal hypoactivity, gray matter deficits, significant decrease in the volume of the hippocampus ${ }^{14}$, as well as temporoparietal dysfunction ${ }^{29}$. Changes in the auditory cortex and volumetric decrease of hippocampus have been implicated in the genesis of PTSD ${ }^{26}$. Some reports on traumatic brain injury describe hippocampal lesions even in mild trauma ${ }^{4}$. Boutros et al. found no significant differences between the S2/S1 ratios of temporal lobe and extra temporal lobe epilepsy patients. In our study, participants had lesions in different brain structures, with partial resection of the frontal, parietal, and occipital lobes and left and right hippocampus. Our findings are in keeping with Rosburg et al. that suggest that different pathological processes may lead to an abnormal sensory gating.

A possible confounding variable was the frequent use of polytherapy by individuals with uncontrolled epilepsy. However, the drugs used were very similar, and there was a clear predominance of carbamazepine in all groups. In individuals with schizophrenia, many studies have shown no change in suppression as a result of the use of typical antipsychotic drugs ${ }^{12,13,17}$. However, there are no reports on the effect of antiepileptic drugs in the P50 paradigm. Grunwald et al. reported that patients made use of therapeutic doses of carbamazepine and did not analyze the S2/S1 ratio or the S1-S2 difference ${ }^{14}$. Kurthen et al. analyzing epilepsy surgery candidates on standard therapy with anticonvulsant drug polytherapy, said that the drugs might systematically alter the P50 responses. On the other hand, they did not find any difference in responses comparing patients under complete drug withdrawal and patients under anticonvulsive treatment ${ }^{22}$. It seems unlikely that these medications may affect P50 suppression since no significant differences between the groups of patients with epilepsy were found, although just one of our patients was not taking anticonvulsive drugs.

The suppression of the P50 potential in the doubleclick paradigm is based primarily on excitatory impulses that cause neuronal responses evidenced by the appearance of an S1 potential. However, if a second stimulus is applied at a short interval, the response to it will be suppressed by the inhibitory mechanism activated by the first stimulus. Some authors suggest that the filtration of P50 involves the inhibition of pyramidal cells by interneurons of the hippocampus. Interneurons would release GABA or adenosine ${ }^{11}$ and thus prevent the release of neurotransmitters, such as glutamate, for many milliseconds. Thus, pyramidal cells of the hippocampus cease to receive excitatory information from the $\mathrm{S} 2$ test stimuli, and, consequently, do not respond to them ${ }^{4,8,10,12}$. Furthermore, lesions in different structures may direct or indirectly result in dysfunction of one or several regions sometimes distant from each other. These findings suggest that the sensory filter in humans, measured by the P50 paradigm, is a complex process of multiple phases, secondary to activity in different brain areas and in different stages, and, thus, not determined by a single structure. Such hypothesis is in line with that proposed by some authors ${ }^{3,6,30}$.

In conclusion, patients with uncontrolled or controlled epilepsy, regardless of surgical treatment of epilepsy, showed a P50 suppression deficit not found in healthy volunteers. This deficit, however, was smaller than that found in individuals with schizophrenia. Moreover, P50 suppression deficit was not associated with seizure control, which may be explained by the intrinsic mechanisms of epilepsy or be a result of surgical resection. Finally, the pattern of suppression in patients with epilepsy in our study was associated with greater amplitude S2 test waves, differently from what was found by most authors in individuals with schizophrenia, who showed mainly a reduction of $\mathrm{S} 1$ conditioning wave amplitudes.

\section{REFERENCES}

1. Zimmerman RS, Sirven Jl. An overview of surgery for chronic seizures. Mayo Clin Proc 2003; 78: 109-117.

2. Pirker S, Schwarzer C, Czech T, et al. Increased expression of GABAA receptor $\beta$-subunits in the hippocampus of patients with temporal lobe epilepsy. J Neuropathol Exp Neurol 2003;62:820-834.

3. Tregellas JR, Ellis J, Shatti S, Du YP, Rojas DC. Increased hippocampal, thalamic and prefrontal hemodynamic response to an urban noise stimulus in schizophrenia. Am J Psychiatry 2009;166:354-360.

4. Arciniegas D, Olincy A, Topkoff J, et al. Impaired auditory gating and P50 nonsuppression following traumatic brain injury. J Neuropsychiatry Clin Neurosci 2000;12: 77-85. 
5. Arciniegas DB, Topkoff JL, Rojas DC, et al. Reduced hippocampal volume in association with $p 50$ nonsuppression following traumatic brain injury. J Neuropsychiatry Clin Neurosci 2001 Spring;13:213-221.

6. Boutros NN, Belger A. Midlatency evoked potentials attenuation and augmentation reflect different aspects of sensory gating. Biol Psychiatry 1999:45:917-922.

7. Fein $G$, Biggins $C$, van Dyke $C$. The auditory P50 response is normal in Alzheimer's disease when measured via a paired click paradigm. Electroencephalogr Clin Neurophysiol 1994;92:536-545.

8. Freedman R, Adler LE, Myles-Worsley M, et al. Inhibitory gating of an evoked response to repeated auditory stimuli in schizophrenic and normal subjects. Human recordings, computer simulation, and an animal model. Arch Gen Psychiatry 1996;53:1114-1121.

9. Ghisolfi ES, Prokopiuk AS, Becker J, et al. The adenosine antagonist theophylline impairs P50 auditory sensory gating in normal subjects. Neuropsychopharmacology 2002;27:629-637.

10. Hetrick WP, Sandman CA, Bunney WE Jr, Jin Y, Potkin SG, White MH. Gender differences in gating of the auditory evoked potential in normal subjects. Biol Psychiatry 1996;39:51-58.

11. Jin Y, Bunney WE Jr, Sandman CA, et al. Is P50 suppression a measure of sensory gating in schizophrenia? Biol Psychiatry 1998;43:873-878.

12. Nagamoto HT, Adler LE, Waldo MC, Griffith J, Freedman R. Gating of auditory response in schizophrenics and normal controls. Effects of recording site and stimulation interval on the P50 wave. Schizophr Res 1991;4:31-40.

13. Siegel C, Waldo M, Mizner G, Adler LE, Freedman R. Deficits in sensory gating in schizophrenic patients and their relatives. Evidence obtained with auditory evoked responses. Arch Gen Psychiatry 1984;41:607-612.

14. Grunwald T, Boutros NN, Pezer N, et al. Neuronal substrates of sensory gating within the human brain. Biol Psychiatry 2003;53:511-519.

15. Uc EY, Skinner RD, Rodnitzky RL, Garcia-Rill E. The midlatency auditory evoked potential P50 is abnormal in Huntington's disease. J Neurol Sci 2003:212:1-5.

16. Ambrosini A, De Pasqua V, Áfra J, Sandor PS, Schoenen J. Reduced gating of middle-latency auditory evoked potentials (P50) in migraine patients: another indication of abnormal sensory processing? Neurosci Lett 2001; 306:132-134

17. Becker J, Gomes I, Ghisolfi ES, et al. Clozapine, but not typical antipsychotics, correct P50 suppression deficit in patients with schizophrenia. Clin Neurophysiol 2004;115:396-401.
18. Ghisolfi ES, Maegawa GH, Becker J, et al. Impaired P50 sensory gating in Machado-Joseph disease. Clin Neurophysiol 2004;115:2231-2235.

19. Jin Y, Potkin SG, Patterson JV, Sandman CA, Hetrick WP, Bunney WE Jr. Effects of P50 temporal variability on sensory gating in schizophrenia. Psychiatry Res 1997;70:71-81.

20. Patterson JV, Jin Y, Gierczak M, et al. Effects of temporal variability on p50 and the gating ratio in schizophrenia: a frequency domain adaptive filter single-trial analysis. Arch Gen Psychiatry 2000;57:57-64.

21. Boutros NN, Trautner P, Korzyukov O, et al. Mid-latency auditory-evoked responses and sensory gating in focal epilepsy: a preliminary exploration. J Neuropsychiatry Clin Neurosci 2006;18:409-416.

22. Kurthen $M$, Trautner $P$, Rosburg $T$, et al. Towards a functional topography of sensory gating aeras: invasive P50 recording and electrical stimulation mapping in epilepsy surgery candidates. Psychiatry Res 2007;155: 121-133.

23. Rosburg T, Trautner P, Ludowig E, et al. Sensory gating in epilepsy: effects of the lateralization of hippocampal sclerosis. Clin Neurophys 2008;119: 1310-1319.

24. Weate SJ, Moore JL, Drake ME Jr. Effect of frontal and temporal seizure foci on P50 auditory evoked potentials. Clin Electroencephalogr 1995;26: 214-218.

25. Sheehan DV, Lecrubier Y, Harnett SK, et al. The Mini International Neuropsychiatric Interview (MINI). The development and validation of a structured diagnostic psychiatric interview. J Clin Psychiatry 1998;59:22-33.

26. Ghisolfi ES, Margis R, Becker J, Zanardo AP, Strimitzer IM, Lara DR. Impaired P50 sensory gating in post-traumatic stress disorder secondary to urban violence. Int J Psychophysiol 2004;51:209-214.

27. Fein G, Biggins C, Mackay S. Cocaine abusers have reduced auditory P50 amplitude and suppression compared to both normal controls and alcoholics. Biol Psychiatry 1996;39:955-965.

28. Patrick G, Straumanis JJ, Struve FA, Fitz-Gerald MJ, Leavitt J, Manno JE. Reduced P50 auditory gating response in psychiatrically normal chronic marihuana users: a pilot study. Biol Psychiatry 1999;45:1307-1312.

29. Etchebehere EC, Cendes F, Lopes-Cendes I, et al. Brain single-photon emission computed tomography and magnetic resonance imaging in Machado-Joseph disease. Arch Neurol 2001;58:1257-1263.

30. Weiland BJ, Boutros NN, Moran JM, Tepley N, Bowyer SM. Evidence for a frontal cortex role in both auditory and somatosensory habituation: a MEG study. Neuroimage 2008;42:827-835. 